\title{
Efektifitas Pencampuran Poly Alumunium Chloride (PAC) dan Penyaringan Menggunakan Pasir Zeolit serta Arang Aktif dalam Mengurangi Kandungan Amonia Limbah Cair Industri Kulit
}

\author{
Ilham Widya Tama Nugraha*, Djoko Kustono, Muhammad Al Irsyad \\ Universitas Negeri Malang, Jl. Semarang No. 5 Malang, Jawa Timur, Indonesia \\ *Penulis korespondensi, Surel: nugrahailham112@gmail.com
}

Paper received: 31-9-2021; revised: 14-9-2021; accepted: 21-9-2021

\begin{abstract}
Liquid waste produced by the leather tanning industry is included in the list of hazardous and toxic wastes for the environment because it contains one of the chemicals, namely ammonia. The goal of this study was to minimize ammonia levels in tannery effluent by mixing Poly Aluminum Chloride (PAC) and filtering with activated charcoal and zeolite sand. This research method uses a control group and an experimental group with three repetitions for each type of reagent. After treatment, the ammonia content was tested using a Spectrophotometer. The data was examined using SPSS using the Regression Test to see if there was an effect of treatment on ammonia content reduction, and then the Kruskal Wallis Test in order of mean ranking to find the most effective type and level of treatment. The Mann Whitney test was then used to see how the relationship between the variables affected the results. The result was found that the PAC reagent level of 3.5 grams was the most effective in reducing ammonia to below the specified quality standard. Efforts to reduce ammonia are carried out to prevent the impact of ammonia gas which is harmful to human health.
\end{abstract}

Keywords: liquid waste; ammonia; poly aluminum chloride; charcoal; zeolite

\begin{abstract}
Abstrak
Limbah cair yang dihasilkan oleh industri penyamakan kulit termasuk dalam daftar limbah bahan berbahaya dan beracun bagi lingkungan karena mengandung salah satu bahan kimia yaitu ammonia. Penelitian ini bertujuan untuk meminimalkan kadar amonia pada limbah penyamakan kulit dengan mencampurkan Poly Aluminium Chloride (PAC) dan menyaring dengan arang aktif dan pasir zeolit. Metode penelitian ini menggunakan kelompok kontrol dan kelompok eksperimen dengan tiga kali pengulangan untuk setiap jenis reagen. Setelah perlakuan, kadar amonia diuji menggunakan Spektrofotometer. Hasil dianalisis menggunakan SPSS dengan Uji Regresi untuk mengetahui apakah ada pengaruh pemberian perlakuan terhadap penurunan kandungan amonia, kemudian untuk mengetahui jenis dan kadar yang paling efektif menggunakan Uji Kruskall Wallis pada urutan ranking mean. Kemudian dilakukan uji Mann Whitney untuk mengetahui pengaruh hubungan setiap variabel. Hasilnya ditemukan bahwa reagen PAC kadar 3,5 gram yang paling efektif mengurangi amonia hingga di bawah baku mutu yang ditentukan. Upaya mereduksi amonia dilakukan untuk mencegah dampak gas amonia yang membahayakan bagi kesehatan manusia.
\end{abstract}

Kata kunci: limbah cair; amonia; poly alumunium chloride; arang; zeolit

\section{Pendahuluan}

Limbah cair merupakan cairan hasil produksi yang biasanya dikumpulkan terlebih dahulu untuk dilakukan proses pengolahan atau terkadang langsung dibuang ke lingkungan sekitar (Lasindrang, 2014). Industri penyamakan kulit menghasilkan limbah cair yang termasuk ke dalam golongan limbah berbahaya untuk lingkungan (Prasetya et al., 2015). Perlu dilakukan pengolahan limbah secara primer, sekunder, dan tersier untuk menurunkan 
beberapa zat berbahaya yang terkandung dalam limbah penyamakan kulit (Murti et al., 2013). Salah satu industri kulit yang memerlukan perhatian khusus yaitu industri penyamakan kulit di Magetan.

Pada data Badan Pusat Statistik Kabupaten Magetan tahun 2018 telah tercatat sebanyak 186 perusahan penyamakan kulit dengan total pekerja 912 karyawan (Badan Pusat Statistik Kabupaten Magetan, 2018). Kegiatan ini didominasi oleh proses penyamakan yang membutuhkan air bersih dalam jumlah besar (Rahayu, 2015). Data tersebut menunjukkan bahwa perusahaan yang beroperasi cukup banyak dan pasti menghasilkan limbah cair yang cukup banyak dari hasil produksinya. Akibatnya potensi pencemaran lingkungan akan semakin tinggi.

Salah satu zat kimia yang terolah namun masih memiliki kadar yang tinggi setelah melalui proses pengolahan primer dan sekunder adalah amonia (Murti et al., 2013). Kadar amonia tersebut dihasilkan akibat penggunaan amonium sulfat pada proses pembuangan kapur (Prahutama \& Purnomo, 2018). Amonia adalah zat yang menyebabkan bau sangat tajam (Simbolon, 2016). Menurut Ramadhian, Endro, \& Mochtar (2014) dalam penelitiannya menjelaskan bau yang dihasilkan dari gas amonia mampu menimbulkan dampak seperti iritasi pada mata, sesak nafas, nyeri dada dan gangguan sistem pernafasan lainnya.

Pengolahan dengan koagulasi adalah satu pengolahan air limbah yang digunakan pada penelitian ini. Koagulasi merupakan proses pencampuran koagulan atau pengendap ke dalam air baku dengan kecepatan perputaran tinggi dalam waktu yang singkat. Poly Aluminum Chloride merupakan koagulan yang digunakan dalam penelitian ini karena dapat berfungsi di pH yang luas, yaitu 6-9,3 (Asmadi \& Suharno, 2012). Berdasarkan penelitian (Rahayu, 2015) dosis koagulan PAC yang efektif menurunkan kadar amonia industri penyamakan kulit di Magetan yaitu 3,5 gr/l dengan keefektifan 98,82\%.

Selanjutnya metode saringan kasar dan halus juga digunakan dalam metode pengolahan limbah cair yang kemudian diadopsi pada penelitian ini. Metode penjernihan air tersebut bernama metode Multi Soil Layering (MSL). Pengertian MSL yaitu metode pengolahan air limbah yang memanfaatkan tanah sebagai media utama dengan cara mempertinggi fungsinya melalui struktur yang dibentuk berupa lapisan campuran tanah dengan material organik, karbon, dan lapisan batuan (zeolit, zeolit pertalite, perlite, dan kerikil atau tergantung pada jenis batuan yang tersedia) (Salmariza \& Sofyan, 2011). Pada metode ini penyaringan dengan memanfaatkan proses adsorpsi atau penyerapan digunakan zeolit dan arang aktif.

Zeolit terbukti mampu mengurangi kadar amonia berdasarkan penelitian (Fauziah et al., 2015) yang menjelaskan bahwa adanya penurunan kadar amonia dalam air setelah perlakuan dengan zeolit. Kemudian untuk penelitian arang aktif yang dilakukan oleh (Lenci Aryani, 2010) membuktikan bahwa limbah cair rumah sakit yang telah disaring menggunakan arang aktif mampu berkurang dengan tingkat efektifitas sebesar 97,96\%. Dari dua penelitian diatas menjadikan pedoman dasar bahwa zeolit dan arang aktif mampu digunakan untuk mereduksi kadar amonia limbah cair industri kulit Magetan. Dengan berkurangnya kandungan amonia tersebut diharapkan bau pada limbah tersebut juga berhasil dikurangi.

Pada penjelasan sebelumnya dapat kita ketahui bahwa kandungan amonia limbah cair industri kulit Magetan berpotensi membahayakan kesehatan manusia. Menurut (Widarti, Wardhini, \& Sarwono, 2015) munculnya gas asam sulfida dan gas amonia dapat menjadi 
tempat berkembang biak bibit penyakit. Namun masih sedikit penelitian yang bertujuan mengurangi kadar amonia limbah industri kulit Magetan dengan menggabungkan metode koagulasi dan MSL. Oleh karena itu peneliti tertarik untuk melakukan penelitian Efektifitas Pencampuran Poly Alumunium Chloride (PAC) dan Penyaringan Menggunakan Pasir Zeolit serta Arang Aktif dalam Mengurangi Kandungan Amonia Limbah Cair Industri Kulit Magetan.

\section{Metode}

\subsection{Jenis Penelitian}

Penelitian ini termasuk jenis penelitian true experiment. Sanjaya dalam (Ismail, 2018) menjelaskan bahwa penelitian eksperimen adalah metode penelitian yang digunakan untuk mengetahui pengaruh dari suatu perlakuan tertentu yang sengaja dilakukan terhadap suatu kondisi tertentu. Kemudian menggunakan pendekatan kuantitatif dengan uji lab untuk mengetahui kandungan amonia limbah cair sebelum dan sesudah diberi perlakuan. Dalam rancangan ini dilakukan pengelompokkan menjadi anggota kelompok kontrol dan kelompok eksperimen.

\subsection{Waktu dan Lokasi Penelitian}

Penelitian dilakukan pada April 2021 sampai Mei 2021. Lokasi penelitian terletak di IPAL Pabrik Industri Penyamakan Kulit Magetan untuk pengambilan sampel dan Laboratorium Kesling Poltekkes Surabaya kampus Magetan untuk proses perlakuan serta Laboratorium Kesehatan Daerah Kabupaten Ngawi untuk pemeriksaan kandungan amonia setelah perlakuan. Kegiatan ini dimulai dengan persiapan penelitian yaitu menyusun proposal, proses pengumpulan data menggunakan instrumen penelitian, pengolahan data, analisis data dan penyusunan hasil penelitian.

\subsection{Prosedur Penelitian}

\subsubsection{Identifikasi Masalah}

Identifikasi masalah dilakukan dengan tujuan untuk mencari penyebab tingginya kandungan amonia dari limbah cair industri kulit yang meresahkan warga Magetan.

\subsubsection{Perumusan Masalah}

Setelah mengidentifikasi permasalahan dilanjutkan dengan merumuskan masalah mengenai upaya pengurangan kadar amonia dengan menambahkan bahan lain berupa PAC dan menyaring dengan lapisan pasir zeolit serta arang aktif kemudian mencari kadar yang paling efektif.

\subsubsection{Penentuan Tujuan Penelitian}

Tujuan penelitian diperlukan untuk merencanakan langkah yang dapat diambil pada penelitian sehingga penelitian dapat menjawab rumusan masalah dan tidak menyimpang dari judul. 


\subsubsection{Perlakuan sampel sesuai variasi kadar dari variabel independen}

Variabel independen akan dibuat menjadi tiga kadar pada masing- masing variabel untuk mengurangi kandungan amonia.

\subsubsection{Pengambilan data dan Penentuan nilai paling efektif dari variabel independen}

Pengambilan data dilakukan dengan uji laboratorium kemudian dilakukan uji statistik dengan SPSS untuk menentukan kadar dari masing-masing variabel independen yang paling efektif dalam mengurangi kadar amonia dari limbah cair industri kulit magetan.

\subsubsection{Kesimpulan dan Saran}

Pada tahap ini hasil dari hipotesis dan rumusan masalah telah ditemukan jawabannya. kemudian akan di berikan rekomendasi dari hasil percobaan yang ditemukan bahwa kadar kandungan yang paling efektif mengurangi kandungan amonia yang menimbulkan bau diharapkan dapat memberikan referensi solusi dari masalah yang sedang diresahkan warga Magetan yang terdampak.

\subsection{Instrumen Penelitian}

Menurut (Sriyatin, 2019), instrumen penelitian merupakan alat untuk mengumpulkan data. Kemudian hasil uji laboratorium ditulis pada lembar penilaian dalam bentuk tabel. Selain itu instrumen untuk pengambilan sampel menggunakan SNI 2008 tentang Air dan air limbah Bagian 59: Metoda pengambilan contoh air limbah. Pada SNI tersebut dijelaskan persyaratan wadah, lokasi pengambilan, dan volume galon air limbah yang diambil, serta metode pengambilan. Untuk baku mutu kadar amonia digunakan instrumen Peraturan Gubernur Jawa Timur nomor 52 Tahun 2014.

\subsection{Analisis Data}

Analisis data pada penelitian ini menggunakan SPSS dengan Uji Regresi untuk menentukan apakah ada hubungan antara variabel bebas dengan variabel terikat, selanjutnya dilakukan Uji Normalitas dan Uji Homogenitas sebagai syarat yang menentukan data harus dianalisis menggunakan parametrik atau non parametrik. Jika data tidak normal dan tidak homogen digunakan Uji Kruskal Wallis dilanjutkan Uji Mann Whitney yang bertujuan untuk mengetahui hubungan antar variabel memiliki perbedaan yang signifikan atau tidak. Namun apabila data berdistribusi normal dan homogen maka memakai Uji Anova One Way. 


\section{Hasil dan Pembahasan}

\subsection{Hasil Percobaan}

Tabel 1. Hasil Uji Coba PAC Terhadap Kandungan Amonia

\begin{tabular}{ccccc}
\hline \multicolumn{5}{c}{ Perlakuan } \\
\hline Pengulangan & Kontrol & $\mathbf{3 , 5}$ gr & $\mathbf{4 ~ g r}$ & $\mathbf{4 , 5} \mathbf{g r}$ \\
\hline 1 & $12 \mathrm{mg} / \mathrm{l}$ & $0,12 \mathrm{mg} / \mathrm{l}$ & $0,69 \mathrm{mg} / \mathrm{l}$ & $1,65 \mathrm{mg} / \mathrm{l}$ \\
2 & & $0,44 \mathrm{mg} / \mathrm{l}$ & $0,69 \mathrm{mg} / \mathrm{l}$ & $1,83 \mathrm{mg} / \mathrm{l}$ \\
3 & & $0,53 \mathrm{mg} / \mathrm{l}$ & $1,44 \mathrm{mg} / 1$ & $1,38 \mathrm{mg} / \mathrm{l}$ \\
Rata-rata & $12 \mathrm{mg} / \mathrm{l}$ & $0,36 \mathrm{mg} / \mathrm{l}$ & $0,94 \mathrm{mg} / \mathrm{l}$ & $1,62 \mathrm{mg} / \mathrm{l}$ \\
\hline
\end{tabular}

Pemberian PAC ke dalam satu liter air limbah pada penelitian ini menggunakan variasi kadar 3,5 gr, 4 gr, dan 4,5 gr. Penelitian ini memanfaatkan proses koagulasi sebagai proses pengendapan padatan tersuspensi pada limbah cair menggunakan koagulan PAC, sehingga membentuk flok-flok halus (Suherman \& Sumawijaya, 2013). Hasil kandungan amonia sampel tanpa pemberian reagen didapatkan sebesar $12 \mathrm{mg} / \mathrm{l}$. Angka tersebut melebihi baku mutu air limbah untuk industri penyamakan kulit yaitu sebesar $10 \mathrm{mg} / \mathrm{l}$ (Peraturan Gubernur Jawa Timur, 2014).

Hasil kadar amonia setelah dicampurkan dengan ragam kadar 3,5 gr, 4 gr, dan 4,5 gr masing-masing dengan kecepatan $80 \mathrm{rpm}$ selama 2 menit. Percobaan pemberian PAC 3,5 gr pada pengulangan pertama menunjukan penurunan dengan hasil 0,12 mg/l. Kemudian pada pengulangan kedua menunjukan penurunan kadar amonia dengan hasil 0,44 mg/l. Selanjutnya pada pengulangan ketiga juga mengalami penurunan kadar amonia dengan hasil $0,53 \mathrm{mg} / \mathrm{l}$. Rata-rata hasil kadar amonia dari percobaan dengan pencampuran menggunakan PAC 3,5 gr adalah $0,36 \mathrm{mg} / \mathrm{l}$.

Sesuai tabel 1 diatas menunjukkan hasil uji amonia setelah pemberian PAC 4 gr pada pengulangan pertama dan kedua menunjukan penurunan dengan hasil 0,69 mg/l. Selanjutnya pada pengulangan ketiga juga mengalami penurunan kadar amonia dengan hasil 1,44 mg/l. Rata-rata hasil kadar amonia dari percobaan dengan pencampuran menggunakan PAC 4 gr adalah $0,94 \mathrm{mg} / \mathrm{l}$. Untuk hasil uji amonia setelah pemberian PAC 4,5 gr pada pengulangan pertama menunjukan penurunan dengan hasil 1,65 mg/l.

Pengulangan kedua menunjukan penurunan kadar amonia dengan hasil 1,83 mg/l. Kemudian pada pengulangan ketiga juga mengalami penurunan kadar amonia dengan hasil $1,38 \mathrm{mg} / \mathrm{l}$. Rata-rata hasil kadar amonia dari percobaan dengan pencampuran menggunakan PAC 4,5 gr adalah 1,62 mg/l. Kesimpulan pada percobaan dengan variabel bebas variasi kadar

Kadar PAC yang memiliki rata-rata paling rendah adalah PAC kadar 3,5 gr dengan nilai $0,36 \mathrm{mg} / \mathrm{l}$. Hasil dari penelitian ini sesuai dengan penelitian yang telah dilakukan oleh (Rahayu, 2015) bahwa pada penelitian tersebut menyatakan kandungan yang sangat efektif mereduksi kandungan amonia limbah cair penyamakan kulit adalah kadar PAC 3,5 gr. Koagulan PAC mampu mereduksi kandungan amonia dalam limbah cair karena memiliki tingkat adsorpsi yang kuat, mempunyai kekuatan lekat, memiliki tingkat sedimentasi yang cepat, merupakan agen penjernih air yang memiliki efisiensi tinggi, cepat dalam proses, aman, dan konsumsinya cukup pada konsentrasi rendah (Yuliati, 2006). 
Sport Science and Health, 3(9), 2021, 709-719

Tabel 2. Hasil Uji Coba penyaringan dengan Arang Aktif pada Kadar Amonia

\begin{tabular}{ccccc}
\hline \multicolumn{5}{c}{ Perlakuan } \\
\hline Pengulangan & Kontrol & $\mathbf{6 0} \mathbf{~ c m}$ & $\mathbf{7 0} \mathbf{~ c m}$ & $\mathbf{8 5} \mathbf{~ c m}$ \\
\hline 1 & $12 \mathrm{mg} / \mathrm{l}$ & $1,26 \mathrm{mg} / \mathrm{l}$ & $1 \mathrm{mg} / \mathrm{l}$ & $1,78 \mathrm{mg} / \mathrm{l}$ \\
2 & & $1,8 \mathrm{mg} / \mathrm{l}$ & $1,43 \mathrm{mg} / \mathrm{l}$ & $0,67 \mathrm{mg} / \mathrm{l}$ \\
3 & & $1,95 \mathrm{mg} / \mathrm{l}$ & $1,58 \mathrm{mg} / \mathrm{l}$ & $0,91 \mathrm{mg} / \mathrm{l}$ \\
Rata-rata & $12 \mathrm{mg} / \mathrm{l}$ & $1,67 \mathrm{mg} / \mathrm{l}$ & $1,34 \mathrm{mg} / \mathrm{l}$ & $1,12 \mathrm{mg} / \mathrm{l}$ \\
\hline
\end{tabular}

Penyaringan satu liter air limbah menggunakan arang aktif pada penelitian ini menggunakan variasi ketebalan $60 \mathrm{~cm}, 70 \mathrm{~cm}$, dan $85 \mathrm{~cm}$. Proses tersebut memanfaatkan metode Multi Soil Layering (MSL) dimana pengolahan air limbah dengan memanfaatkan tanah sebagai media utama dengan cara mempertinggi fungsinya melalui struktur yang dibentuk berupa lapisan karbon, dan material pasir zeolit (Salmariza \& Sofyan, 2011). Hasil kandungan amonia sampel tanpa pemberian reagen didapatkan sebesar $12 \mathrm{mg} / \mathrm{l}$. Angka tersebut melebihi baku mutu air limbah untuk industri penyamakan kulit yaitu sebesar $10 \mathrm{mg} / \mathrm{l}$ (Peraturan Gubernur, Jawa Timur 2014). Berikut adalah hasil kadar amonia setelah disaring dengan variasi arang aktif dengan ketebalan $60 \mathrm{~cm}, 70 \mathrm{~cm}$, dan $85 \mathrm{~cm}$.

Sesuai tabel 2 diatas hasil uji amonia setelah penyaringan dengan arang aktif setebal 60 $\mathrm{cm}$ pada pengulangan pertama menunjukan penurunan dengan hasil 1,26 mg/l. Kemudian pada pengulangan kedua menunjukan penurunan kadar amonia dengan hasil 1,8 mg/l. Selanjutnya pada pengulangan ketiga juga mengalami penurunan kadar amonia dengan hasil $1,95 \mathrm{mg} / \mathrm{l}$. Rata-rata hasil kadar amonia dari percobaan dengan penyaringan menggunakan arang aktif setebal $60 \mathrm{~cm}$ adalah 1,67 mg/l.

Kemudian untuk hasil uji amonia setelah penyaringan dengan zeolit setebal $70 \mathrm{~cm}$ pada pengulangan pertama menunjukan penurunan dari hasil kelompok kontrol dengan hasil 1 mg/l. Pada pengulangan kedua menunjukan penurunan kadar amonia dengan hasil 1,43 mg/l. Selanjutnya pada pengulangan ketiga juga mengalami penurunan kadar amonia dengan hasil $1,58 \mathrm{mg} / \mathrm{l}$. Rata-rata hasil kadar amonia dari percobaan dengan penyaringan menggunakan zeolit setebal $70 \mathrm{~cm}$ adalah $1,34 \mathrm{mg} / \mathrm{l}$.

Hasil uji amonia setelah penyaringan dengan arang aktif setebal $85 \mathrm{~cm}$ pada pengulangan pertama menunjukan penurunan dari hasil kelompok kontrol dengan hasil 1,78 $\mathrm{mg} / \mathrm{l}$. Kemudian pada pengulangan kedua menunjukan penurunan kadar amonia dengan hasil $0,67 \mathrm{mg} / \mathrm{l}$. Selanjutnya pada pengulangan ketiga juga mengalami penurunan kadar amonia dengan hasil $0,91 \mathrm{mg} / \mathrm{l}$. Rata-rata hasil kadar amonia dari percobaan dengan penyaringan menggunakan arang aktif setebal $85 \mathrm{~cm}$ adalah $1,12 \mathrm{mg} / \mathrm{l}$.

Kesimpulan pada percobaan penyaringan dengan variabel bebas variasi ketebalan arang aktif menunjukan semua hasil mengalami penurunan dengan rata-rata nilai yang paling rendah $1,12 \mathrm{mg} / \mathrm{l}$ yaitu pada kadar arang aktif setebal $85 \mathrm{~cm}$. Penelitian ini selaras dengan penelitian yang telah dilakukan oleh (Lenci Aryani, 2010) bahwa ketebalan arang aktif yang paling efektif dalam mereduksi kandungan amonia limbah cair di RSUD Semarang sebesar $85 \mathrm{~cm}$. Arang aktif mampu menurunkan kandungan amonia limbah cair karena memiliki kemampuan daya serap yang baik yang dikenal dengan istilah adsorban (Aisyah, 2019). Semakin tebal lapisan arang aktif maka semakin tinggi dalam mereduksi kandungan amonia dalam limbah cair. 
Sport Science and Health, 3(9), 2021, 709-719

Tabel 3. Hasil Uji Coba Penyaringan dengan Zeolit pada Kadar Amonia

\begin{tabular}{ccccc}
\hline \multicolumn{5}{c}{ Perlakuan } \\
\hline Pengulangan & Kontrol & $\mathbf{6 0} \mathbf{~ c m}$ & $\mathbf{7 0} \mathbf{~ c m}$ & $\mathbf{8 5} \mathbf{~ c m}$ \\
\hline 1 & $12 \mathrm{mg} / \mathrm{l}$ & $2,9 \mathrm{mg} / \mathrm{l}$ & $1,79 \mathrm{mg} / \mathrm{l}$ & $2,48 \mathrm{mg} / \mathrm{l}$ \\
2 & & $2,25 \mathrm{mg} / \mathrm{l}$ & $2,38 \mathrm{mg} / 1$ & $2,04 \mathrm{mg} / 1$ \\
3 & & $1,96 \mathrm{mg} / 1$ & $2,26 \mathrm{mg} / 1$ & $1,07 \mathrm{mg} / 1$ \\
Rata-rata & $12 \mathrm{mg} / \mathrm{l}$ & $2,37 \mathrm{mg} / \mathrm{l}$ & $2,14 \mathrm{mg} / \mathrm{l}$ & $1,86 \mathrm{mg} / \mathrm{l}$ \\
\hline
\end{tabular}

Penyaringan satu liter air limbah menggunakan zeolit pada penelitian ini menggunakan variasi ketebalan $60 \mathrm{~cm}, 70 \mathrm{~cm}$, dan $85 \mathrm{~cm}$. Proses tersebut memanfaatkan metode Multi Soil Layering (MSL) dimana pengolahan air limbah dengan memanfaatkan tanah sebagai media utama dengan cara mempertinggi fungsinya melalui struktur yang berupa lapisan karbon, dan material pasir zeolit (Salmariza \& Sofyan, 2011). Hasil kandungan amonia sampel tanpa pemberian reagen didapatkan sebesar $12 \mathrm{mg} / \mathrm{l}$. Angka tersebut melebihi baku mutu air limbah untuk industri penyamakan kulit yaitu sebesar $10 \mathrm{mg} / \mathrm{l}$ (Peraturan Gubernur Jatim, No. 52, 2014). Berikut adalah hasil kadar amonia setelah disaring dengan variasi zeolit dengan ketebalan $60 \mathrm{~cm}, 70 \mathrm{~cm}$, dan $85 \mathrm{~cm}$.

Sesuai tabel 3 diatas hasil uji amonia setelah penyaringan dengan zeolit setebal $60 \mathrm{~cm}$ pada pengulangan pertama menunjukan penurunan dari hasil kelompok kontrol dengan hasil 2,9 mg/l. Kemudian pada pengulangan kedua menunjukan penurunan kadar amonia dengan hasil $2,25 \mathrm{mg} / \mathrm{l}$. Selanjutnya pada pengulangan ketiga juga mengalami penurunan kadar amonia dengan hasil 1,96 mg/l. Rata-rata hasil kadar amonia dari percobaan dengan penyaringan menggunakan zeolit setebal $60 \mathrm{~cm}$ adalah $2,37 \mathrm{mg} / \mathrm{l}$.

Kemudian untuk hasil uji amonia setelah penyaringan dengan zeolit setebal $70 \mathrm{~cm}$ pada pengulangan pertama menunjukan penurunan dari hasil kelompok kontrol dengan hasil 1,79 $\mathrm{mg} / \mathrm{l}$. Pada pengulangan kedua menunjukan penurunan kadar amonia dengan hasil 2,38 mg/l. Selanjutnya pada pengulangan ketiga juga mengalami penurunan kadar amonia dengan hasil $2,26 \mathrm{mg} / \mathrm{l}$. Rata-rata hasil kadar amonia dari percobaan dengan penyaringan menggunakan zeolit setebal $70 \mathrm{~cm}$ adalah $2,14 \mathrm{mg} / \mathrm{l}$.

Hasil uji amonia setelah penyaringan dengan zeolit setebal $85 \mathrm{~cm}$ pada pengulangan pertama menunjukan penurunan dari hasil kelompok kontrol dengan hasil 2,48 mg/l. Kemudian pada pengulangan kedua menunjukan penurunan kadar amonia dengan hasil 2,04 $\mathrm{mg} / \mathrm{l}$. Selanjutnya pada pengulangan ketiga juga mengalami penurunan kadar amonia dengan hasil $1,07 \mathrm{mg} / \mathrm{l}$. Rata-rata hasil kadar amonia dari percobaan dengan penyaringan menggunakan zeolit setebal $85 \mathrm{~cm}$ adalah $1,86 \mathrm{mg} / \mathrm{l}$.

Kesimpulan pada percobaan penyaringan dengan variabel bebas variasi ketebalan zeolit menunjukan semua hasil mengalami penurunan dengan rata-rata nilai yang paling rendah 1,86 $\mathrm{mg} / \mathrm{l}$ yaitu pada kadar zeolit setebal $85 \mathrm{~cm}$. Penelitian ini selaras dengan penelitian sebelumnya yang menjelaskan bahwa semakin tebal zeolit maka semakin tinggi dalam mereduksi kandungan amonia (Fauziah et al., 2015). Zeolit mampu mereduksi amonia karena memiliki sifat sebagai penyaring, pemisah, penyerap, pengganti ion serta berperan menjadi katalisator (Rini \& Lingga, 2010). Selain itu menurut (Ronny \& Saleh, 2018) zeolit mempunyai struktur pori terbuka dengan area permukaan besar sehingga kemampuannya dalam mengadsorpsi amonia dalam air limbah semakin tinggi. 


\subsection{Uji Hipotesis}

Uji hipotesis pada penelitian ini menggunakan Uji Regresi. Analisis regresi yaitu alat statistik yang digunakan untuk mengetahui hubungan antara satu atau beberapa variabel bebas terhadap satu buah variabel terikat. Berikut hasil Uji Koefisiennya.

Tabel 4. Hasil Uji Coefficients Regresi

\begin{tabular}{cc}
\hline & Sig. \\
\hline Reagen & 0,030 \\
\hline
\end{tabular}

Pada tabel koefisien diatas menunjukan bahwa nilai sig. sebesar 0,030 dan kurang dari sig. 0,05 maka dapat diartikan bahwa variabel bebas mempengaruhi nyata terhadap variabel terikat. Pada penelitian ini berarti reagen berpengaruh terhadap hasil amonia.

Selanjutnya dilakukan Uji Kruskall Wallis karena nilai uji homogenitas tidak terpenuhi. Uji ini bertujuan untuk mengetahui apakah terdapat perbedaan yang signifikan antara ratarata lebih dari dua kelompok. Berikut adalah hasil uji Kruskall Wallis menggunakan aplikasi SPSS. Pada penelitian ini pengaruh signifikansi antar variabel dilihat dari uji Post Hoc menggunakan uji Mann Whitney. Berikut adalah hasil analisisnya.

Tabel 5. Test Statistics

\begin{tabular}{lc}
\hline & Hasil Amonia \\
\hline Asymp. Sig. & 0,005 \\
\hline
\end{tabular}

Pada tabel Test Statistics diatas menunjukan bahwa nilai Asymp. Sig sebesar 0,005 $<0,05$ maka dapat dinyatakan bahwa ada pengaruh variabel independen terhadap variabel dependen. Selanjutnya yaitu melihat pada hasil rank mean sebagai berikut:

Tabel 6. Ranking Mean

\begin{tabular}{llcc}
\hline \multicolumn{1}{c}{ Reagen } & N & Mean Rank \\
\hline Hasil Amonia & 3 & 29,00 \\
& Kadar 0 & 3 & 2,00 \\
& Kadar reagen PAC 3,5 g & 3 & 8,00 \\
& Kadar reagen PAC 4 g & 3 & 15,00 \\
& Kadar reagen PAC 4,5 g & 3 & 16,00 \\
& Kadar reagen karbon 60 cm & 3 & 11,33 \\
& Kadar reagen karbon 70 cm & 3 & 9,00 \\
Kadar reagen karbon 85 cm & 3 & 23,67 \\
Kadar reagen zeolit 60 cm & 3 & 22,00 \\
Kadar reagen zeolit 70 cm & 3 & 19,00 \\
Kadar reagen zeolit 85 cm & 3 & \\
& Total & 30 & \\
\hline
\end{tabular}

Pada tabel rank mean diatas menunjukkan bahwa reagen PAC 3,5 gram memiliki mean yang paling rendah diantara reagen yang lain, maka kesimpulannya adalah kadar yang paling berpengaruh mengurangi amonia adalah reagen PAC kadar 3,5 gram dengan nilai mean 2,00. 


\subsection{Uji Mann Whitney}

Pada uji sebelumnya yaitu Uji Kruskall Wallis hanya dapat mengetahui apakah ditemukan perbedaan yang bermakna secara statistik tanpa bisa mengetahui antar perlakuan mana yang berbeda, oleh karena itu dilanjutkan uji Post Hoc. Selanjutnya untuk uji Post Hoc digunakan uji Mann Whitney dengan maksud menguji perbedaan mean antara satu kelompok atau perlakuan dengan perlakuan lainnya. Uji Mann Whitney dilakukan satu persatu mulai reagen 0 dengan reagen PAC 3,5 gram sampai dengan reagen zeolit $70 \mathrm{~cm}$ dengan reagen zeolit $85 \mathrm{~cm}$. Berikut hasil ujinya:

Tabel 7. Hasil Uji Mann Whitney antar Reagen

\begin{tabular}{|c|c|c|c|c|}
\hline & Variabel & $\begin{array}{c}<0,05 \\
\text { atau } \\
=0,05\end{array}$ & $>0,05$ & Keterangan \\
\hline Reagen 0 & Reagen PAC 3,5 g & 0,037 & & Ada Perbedaan \\
\hline \multirow[t]{8}{*}{ dengan } & Reagen PAC $4 \mathrm{~g}$ & 0,034 & & Ada Perbedaan \\
\hline & Reagen PAC 4,5 g & 0,037 & & Ada Perbedaan \\
\hline & Reagen Karbon $60 \mathrm{~cm}$ & 0,037 & & Ada Perbedaan \\
\hline & Reagen Karbon $70 \mathrm{~cm}$ & 0,037 & & Ada Perbedaan \\
\hline & Reagen Karbon 85 cm & 0,037 & & Ada Perbedaan \\
\hline & Reagen Zeolit $60 \mathrm{~cm}$ & 0,037 & & Ada Perbedaan \\
\hline & Reagen Zeolit $70 \mathrm{~cm}$ & 0,037 & & Ada Perbedaan \\
\hline & Reagen Zeolit $85 \mathrm{~cm}$ & 0,037 & & Ada Perbedaan \\
\hline Reagen PAC & Reagen PAC $4 \mathrm{~g}$ & 0,046 & & Ada Perbedaan \\
\hline \multirow[t]{7}{*}{3,5 g dengan } & Reagen PAC 4,5 g & 0,050 & & Ada Perbedaan \\
\hline & Reagen Karbon $60 \mathrm{~cm}$ & 0,050 & & Ada Perbedaan \\
\hline & Reagen Karbon $70 \mathrm{~cm}$ & 0,050 & & Ada Perbedaan \\
\hline & Reagen Karbon $85 \mathrm{~cm}$ & 0,050 & & Ada Perbedaan \\
\hline & Reagen Zeolit $60 \mathrm{~cm}$ & 0,050 & & Ada Perbedaan \\
\hline & Reagen Zeolit $70 \mathrm{~cm}$ & 0,050 & & Ada Perbedaan \\
\hline & Reagen Zeolit $85 \mathrm{~cm}$ & 0,050 & & Ada Perbedaan \\
\hline Reagen PAC & Reagen PAC 4,5 g & & 0,121 & Tidak Ada Perbedaan \\
\hline \multirow[t]{6}{*}{$4 \mathrm{~g}$ dengan } & Reagen Karbon $60 \mathrm{~cm}$ & & 0,121 & Tidak Ada Perbedaan \\
\hline & Reagen Karbon $70 \mathrm{~cm}$ & & 0,268 & Tidak Ada Perbedaan \\
\hline & Reagen Karbon $85 \mathrm{~cm}$ & & 0,825 & Tidak Ada Perbedaan \\
\hline & Reagen Zeolit $60 \mathrm{~cm}$ & 0,046 & & Ada Perbedaan \\
\hline & Reagen Zeolit $70 \mathrm{~cm}$ & 0,046 & & Ada Perbedaan \\
\hline & Reagen Zeolit $85 \mathrm{~cm}$ & & 0,121 & Tidak Ada Perbedaan \\
\hline Reagen PAC & Reagen Karbon $60 \mathrm{~cm}$ & & 0,827 & Tidak Ada Perbedaan \\
\hline \multirow[t]{5}{*}{ 4,5 g dengan } & Reagen Karbon $70 \mathrm{~cm}$ & & 0,275 & Tidak Ada Perbedaan \\
\hline & Reagen Karbon $85 \mathrm{~cm}$ & & 0,275 & Tidak Ada Perbedaan \\
\hline & Reagen Zeolit $60 \mathrm{~cm}$ & 0,050 & & Ada Perbedaan \\
\hline & Reagen Zeolit $70 \mathrm{~cm}$ & & 0,127 & Tidak Ada Perbedaan \\
\hline & Reagen Zeolit $85 \mathrm{~cm}$ & & 0,513 & Tidak Ada Perbedaan \\
\hline Reagen & Reagen Karbon $70 \mathrm{~cm}$ & & 0,275 & Tidak Ada Perbedaan \\
\hline Karbon 60 & Reagen Karbon $85 \mathrm{~cm}$ & & 0,127 & Tidak Ada Perbedaan \\
\hline \multirow[t]{3}{*}{ cm dengan } & Reagen Zeolit $60 \mathrm{~cm}$ & 0,050 & & Ada Perbedaan \\
\hline & Reagen Zeolit $70 \mathrm{~cm}$ & & 0,275 & Tidak Ada Perbedaan \\
\hline & Reagen Zeolit 85 cm & & 0,513 & Tidak Ada Perbedaan \\
\hline Reagen & Reagen Karbon $85 \mathrm{~cm}$ & & 0,513 & Tidak Ada Perbedaan \\
\hline Karbon 70 & Reagen Zeolit $60 \mathrm{~cm}$ & 0,050 & & Ada Perbedaan \\
\hline \multirow[t]{3}{*}{ cm dengan } & Reagen Zeolit $70 \mathrm{~cm}$ & 0,050 & & Ada Perbedaan \\
\hline & Reagen Zeolit $85 \mathrm{~cm}$ & & 0,275 & Tidak Ada Perbedaan \\
\hline & Reagen Zeolit $60 \mathrm{~cm}$ & 0,050 & & Ada Perbedaan \\
\hline
\end{tabular}




\begin{tabular}{|c|c|c|c|c|}
\hline & Variabel & $\begin{array}{c}<0,05 \\
\text { atau } \\
=0,05\end{array}$ & $>0,05$ & Keterangan \\
\hline Reagen & Reagen Zeolit $70 \mathrm{~cm}$ & 0,050 & & Ada Perbedaan \\
\hline $\begin{array}{l}\text { Karbon } 85 \\
\mathrm{~cm} \text { dengan }\end{array}$ & Reagen Zeolit $85 \mathrm{~cm}$ & & 0,127 & Tidak Ada Perbedaan \\
\hline $\begin{array}{l}\text { Reagen } \\
\text { Zeolit } 60 \mathrm{~cm}\end{array}$ & Reagen Zeolit $70 \mathrm{~cm}$ & & 0,827 & Tidak Ada Perbedaan \\
\hline dengan & Reagen Zeolit $85 \mathrm{~cm}$ & & 0,513 & Tidak Ada Perbedaan \\
\hline $\begin{array}{l}\text { Reagen } \\
\text { Zeolit } 70 \mathrm{~cm} \\
\text { dengan }\end{array}$ & Reagen Zeolit $85 \mathrm{~cm}$ & & 0,827 & Tidak Ada Perbedaan \\
\hline
\end{tabular}

Pada tabel diatas menunjukan hubungan antar setiap reagen satu dengan yang lain telah ditemukan bahwa yang memiliki perbedaan dengan nilai sig. kurang dari atau sama dengan 0,05 sedangkan yang tidak memiliki perbedaan memiliki nilai sig. lebih dari 0,05.

\section{Simpulan}

Kesimpulan dari penelitian ini adalah hasil antara reagen PAC, arang, dan zeolit yang paling efektif mereduksi amonia dalam limbah cair industri kulit adalah reagen PAC. Pemberian reagen PAC 3,5 gr, 4 gr, dan 4,5 gr semua mampu mereduksi amonia dalam limbah cair hingga di bawah baku mutu. Kadar PAC yang paling efektif dalam mereduksi amonia adalah PAC 3,5 gr dengan rata-rata 0,36 mg/l. Kemudian untuk reagen arang $60 \mathrm{~cm}, 70 \mathrm{~cm}$, dan $85 \mathrm{~cm}$, semua mampu mereduksi amonia hingga di bawah baku mutu dengan hasil kadar yang paling efektif yaitu reagen arang $85 \mathrm{~cm}$ dengan nilai rata-rata $1,12 \mathrm{mg} / \mathrm{l}$. Selanjutnya untuk reagen zeolit $60 \mathrm{~cm}, 70 \mathrm{~cm}$, dan $85 \mathrm{~cm}$ semua mampu mereduksi amonia hingga di bawah baku mutu. Reagen zeolit yang paling efektif adalah reagen $85 \mathrm{~cm}$ karena mampu mereduksi amonia hingga rata-rata $1,86 \mathrm{mg} / \mathrm{l}$.

\section{Daftar Rujukan}

Aisyah, I. (2019). Multimanfaat Arang Dan Asap Cair Limbah Biomasa. Retrieved from https://books.google.co.id/books?id=LOeiDwAAQBAJ\&pg=PA48\&dq=pengertian+zat+arang+aktif+ad alah\&hl=id\&sa=X\&ved=2ahUKEwjkmNqU1fzrAhXhX3wKHSz4CsQQ6AEwAHoECAUQAg\#v=onepage $\& q=$ pengertian zat arang aktif adalah\&f=false

Asmadi, S., \& Suharno. (2012). Dasar-Dasar Teknologi Pengolahan Air Limbah. Yogyakarta: Gosyen Publishing.

Badan Pusat Statistik Kabupaten Magetan. (2018). Retrieved September 16, 2020, from https://magetankab.bps.go.id/statictable/2019/11/04/365/jumlah-perusahaan-tenaga-kerja-dannilai-produksi-menurut-jenis-industri-di-kabupaten-magetan-2018.html

Fauziah, R., Jurusan, D., Lingkungan, K., Kesehatan, P., Jambi, K., \& Kunci, K. (2015). Efektifitas Ketebalan Zeolit Dalam Menurunkan Amoniak ( NH 4). XIII, 167-169.

Gubernur. (2014). Peraturan Gubernur Jawa Timur No. 52 Tahun 2014. 1-6.

Ismail, F. (2018). Statistika Untuk Penelitian Pendidikan dan Ilmu-Ilmu Sosial. Retrieved from https://books.google.co.id/books?id=D9B1DwAAQBAJ\&printsec=frontcover\&dq=Ismail+F.+2018.+Sa tistika+Untuk+Penelitian+Pendidikan+dan+Ilmu-

Ilmu+Sosial.+Jakarta+:+Prenadamedia+Group\&hl=id\&sa=X\&ved=2ahUKEwij9IjiuO_rAhXCeisKHV1dA J0Q6AEwAXoECAAQAg\#v=onepage \&q\&f=f

Lasindrang, M. (2014). Adsorpsi Pencemaran Limbah Cair Industri Penyamakan Kulit Oleh Kitosan Yang Melapisi Arang Aktif Tempurung Kelapa. Jurnal Teknosains, 3(2). https://doi.org/10.22146/teknosains.6026 
Lenci Aryani. (2010). Efektivitas Variasi Ketebalan Arang Aktif untuk Menurunkan Kadar Amoniak (NH3) dalam Limbah Cair Rumah Sakit Umum Daerah Tugurejo Semarang. 006057, 6057. Retrieved from http://eprints.undip.ac.id/31906/

Murti, R. S., Purwanti, C. M. H., \& Suyatini, S. (2013). Adsorpsi amonia dari limbah cair industri penyamakan kulit menggunakan abu terbang bagas. Majalah Kulit, Karet, Dan Plastik, 29(2), 85. https://doi.org/10.20543/mkkp.v29i2.195

Peraturan Gubernur Jawa Timur nomor 52 Tahun 2014. (2014). Retrieved from https://dlh.ponorogo.go.id/wp-content/uploads/2018/05/Pergub-Jatim-Nomor-52-Tahun-2014Tentang-Baku-Mutu-Limbah.pdf

Prahutama, P., \& Purnomo, Y. S. (2018). Pengolahan Limbah Cair Industri Penyamakan Kulit Dengan Adsorpsi Abu Terbang Bagas. Studi, Program Lingkungan, Teknik Pembangunan, Universitas Veteran, Nasional Timur, Jawa, 10(1), 5-10.

Prasetya, V. N., Susanawati, L. D., Widiatmono, B. R., \& Sumberdaya, J. (2015). Jurnal Sumberdaya Alam dan Lingkungan Penentuan Daya Tampung Sungai Badek Terhadap Beban Pencemar Akibat Limbah Cair Penyamakan Kulit di Kelurahan Ciptomulyo , Malang River Capacity Determination from Tannery Liquid Waste of Badek River in Ciptomulyo Coun. Jurnal Sumberdaya Alam Dan Lingkungan, 2(2), 1724. Retrieved from https://jsal.ub.ac.id/index.php/jsal/article/view/182/157

Rahayu, H. L. (2015). Keefektifan Variasi Dosis PAC (Polyalumunium Chloride) Dalam Menurunkan Kadar Amonia Air Limbah Iindustri Penyamakan Kulit di Magetan.

Ramadhian, L., Endro, S., \& Mochtar, H. (2014). Pengaruh Jumlah Kotoran Sapi Terhadap Konsentrasi Gas Amonia (Nh3) Di Dalam Rumah ( Studi Kasus: Desa Dalangan Kelurahan Sumogawe, Kecamatan Getasan, Kabupaten Semarang). Jurnal Teknik Lingkungan. Retrieved from https://www.neliti.com/publications/134179/pengaruh-jumlah-kotoran-sapi-terhadap-konsentrasigas-amonia-nh3-di-dalam-rumah

Rini, D. K., \& Lingga, F. A. (2010). Optimasi Aktivasi Zeolit Alam Untuk Dehumidifikasi. Retrieved from http://eprints.undip.ac.id/13791/

Ronny, \& Saleh, M. (2018). Penurunan Kadar COD dengan Metode Filtrasi Multimedia Filter pada Air Limbah Laundry. Jurnal Penelitian, $4, \quad 51 . \quad$ Retrieved from http://103.55.216.56/index.php/higiene/article/view/5839

Salmariza, \& Sofyan. (2011). Aplikasi Metoda MSL (Multi Soil Layering) untuk Mengolah Air Limbah Industri Edilble Oil. Riset Industri, 3(1), 227-238.

Simbolon, A. M. (2016). Penetapan Kadar Amonia Dalam Air Bersih Dengan Metode Spektrofotometri Visible. SP - Analis Farmasi Dan Makanan. Retrieved from http://repository.usu.ac.id/handle/123456789/66576

Sriyatin. (2019). Evaluasi Pembelajaran Matematika. Jatim: Uwais Inspirasi Indonesia.

Suherman, D., \& Sumawijaya, N. (2013). Menghilangkan Warna Dan Zat Organik Air Gambut Dengan Metode Koagulasi-Flokulasi Suasana Basa. Indonesian Journal of Geology and Mining, 23(2), 127-140. Retrieved from http://jrisetgeotam.com/index.php/jrisgeotam/article/view/75/pdf_29

Widarti, B. N., Wardhini, W. K., \& Sarwono, E. (2015). Pengaruh Rasio C/N Bahan Baku Pada Pembuatan Kompos Dari Kubis dan Kulit Pisang. Jurnal Integrasi Proses, 5(2), 75-80.

Yuliati, S. (2006). Proses Koagulasi - Flokulasi Pada Pengolahan Tersier Limbah Cair PT. Capsugel Indonesia. $I P B \quad$ Repository. Retrieved from https://repository.ipb.ac.id/handle/123456789/32848\#: :text=Proses koagulasi - flokulasi merupakan salah,cepat dalam bentuk larutan tercampur. 